\title{
How $\mathrm{OH}$ and $\mathrm{O}^{-}$groups affect electronic structure of meta-substituted and para-substituted phenols and phenolates
}

\author{
Mozhgan Shahamirian $^{1} \cdot$ Halina Szatylowicz $^{2}$ (D) Tadeusz M. Krygowski $^{3}$
}

Received: 1 March 2017 / Accepted: 3 May 2017 /Published online: 23 May 2017

(C) The Author(s) 2017. This article is an open access publication

\begin{abstract}
An application of two independent quantum chemistry-based concepts, a substituent effect stabilization energy (SESE) and a charge of the substituent active region (cSAR), for describing substituent effects allows to investigate a nature of mutual interactions between substituents. The B3LYP/6-311++G(d,p) method is employed to examine changes in properties of a reaction center $\mathrm{Y}\left(\mathrm{Y}=\mathrm{OH}\right.$ or $\mathrm{O}^{-}$groups $)$ and a transmitting moiety (the benzene ring) due to substituent effects in a series of meta-X-substituted and para-X-substituted phenol and phenolate derivatives $\left(\mathrm{X}=\mathrm{NMe}_{2}, \mathrm{NH}_{2}, \mathrm{OH}, \mathrm{OMe}\right.$, $\mathrm{CH}_{3}, \mathrm{H}, \mathrm{F}, \mathrm{Cl}, \mathrm{CF}_{3}, \mathrm{CN}, \mathrm{CHO}, \mathrm{COCl}, \mathrm{COMe}, \mathrm{CONH}_{2}, \mathrm{COOH}$, $\left.\mathrm{NO}_{2}, \mathrm{NO}\right)$. HOMA, NICS(1) and $p$ EDA parameters are used to characterize $\pi$-electron delocalization of the transmitting moiety. Relations between $\operatorname{cSAR}(\mathrm{X})$ and $\sigma$ constants show almost identical sensitivity of the substituent effect in meta-substituted phenol and phenolate derivatives, whereas in para-substituted analogs, different kinds of intramolecular interactions have
\end{abstract}

This paper is dedicated to Professor Lou Massa on the occasion of his Festschrift.

Electronic supplementary material The online version of this article (doi:10.1007/s11224-017-0965-4) contains supplementary material, which is available to authorized users.

Halina Szatylowicz

halina@ch.pw.edu.pl

Tadeusz M. Krygowski

tmkryg@ chem.uw.edu.pl

1 Department of Chemistry, Faculty of Science, Sarvestan Branch, Islamic Azad University, Sarvestan, Iran

2 Faculty of Chemistry, Warsaw University of Technology, Noakowskiego 3, 00-664 Warsaw, Poland

3 Faculty of Chemistry, University of Warsaw, Pasteura 1, 02-093 Warsaw, Poland been revealed. Due to electron attractive property of $\mathrm{OH}$ group in meta position, dependences of $\operatorname{cSAR}(\mathrm{X})$ on SESE show a dramatically different picture of interaction in meta-substituted phenols as compared to that found for all other series studied. Moreover, this group affects in a different way the electronattracting and electron-donating substituents in meta position. A clear substituent effect on $\pi$-electron delocalization of the benzene ring is observed only in para-substituted phenolate derivatives. The application of $\operatorname{cSAR}(\mathrm{X})$ parameter allows to estimate a difference between its value for a particular substituent in meta and para derivatives. In some cases, this difference amounts up to $\sim 53 \%$ of the range of $\operatorname{cSAR}(\mathrm{X})$ variability.

Keywords substituent effects · electronic structure · molecular modeling - substituent effect stabilization energy · charge of the substituent active region

\section{Introduction}

There are a lot of reasons causing hydroxy and hydroxylate groups to form a pair of substituents of a great importance. Firstly, they can interchange from one to another depending on the environment [1]. In cases of an interaction with strong bases, $\mathrm{OH}$ group is easily transformed into $\mathrm{O}^{-}$group. Secondly, they have a possibility to act either as the H-bond donor $(\mathrm{OH})$ or acceptor $\left(\mathrm{O}^{-}\right)$; for a review, see Gilli and Gilli [2]. As substituents $(X)$ interacting in a classical way with reaction site $(\mathrm{Y})$ through the transmitting moiety $\mathrm{R}$, schematically $\mathrm{X}-\mathrm{R}-\mathrm{Y}$, both $\mathrm{OH}$ and $\mathrm{O}^{-}$exhibit very different properties exemplified in Table 1 by means of substituent constants [3].

As we see, $\mathrm{OH}$ group in meta position acts even as an electron-accepting substituent with $\sigma>0$, whereas in all other cases, $\sigma<0$, and hence, both $\mathrm{OH}$ and $\mathrm{O}^{-}$groups exhibit electron-donating properties. Hydroxylate group $\left(\mathrm{O}^{-}\right)$is always 
Table 1. Substituent constants in dependence on position (meta- and reaction site taken from Ref. [3]. para-) and nature of a

\begin{tabular}{lrr}
\hline Substituent constant & \multicolumn{1}{l}{$\mathrm{OH}$} & $\mathrm{O}^{-}$ \\
\hline$\sigma_{\mathrm{m}}$ & 0.12 & -0.47 \\
$\sigma_{\mathrm{p}}$ & -0.37 & -0.81 \\
$\sigma_{\mathrm{p}}{ }^{+}$ & -0.92 & -2.30 \\
$\sigma_{\mathrm{p}}{ }^{-}$ & -0.37 & -0.82 \\
\hline
\end{tabular}

much stronger electron-donating substituent than $\mathrm{OH}$ group. All these data are obtained from the model reactions: the Hammett constants from acid/base equilibria of benzoic acid derivatives and $\sigma_{\mathrm{p}}{ }^{+}$from the kinetic data of solvolysis of dimethyl-diphenyl-carbinylchloride $[4,5]$. It is important to note that the changeability of electron accepting/donating properties of both groups is very large. An application of the abovementioned substituent constants is somewhat limited to systems in which we are able to assume a similar nature of substituent effect to that which works in an appropriate model reaction. Unfortunately, this kind of a priori assumption is not always justified. A quantum chemical modeling allows to look at these problems independently from the model reactions/processes. The substituent effect may be characterized by quantitative descriptors which can be verified firstly by a comparison with the traditional, empiric substituent constant. Substituent effects in phenol and phenoxide ion derivatives were theoretically described by means of molecular orbital calculations [6], however, without a possibility of an effective estimation of substituent effect descriptors in a given molecular system.

Recently, two quantum chemical-based models have been successfully applied for describing SE: cSAR and substituent effect stabilization energy (SESE). The cSAR(X) approach (an acronym from charge of the Substituent Active Region) describes the electron attracting or donating property of the substituent $\mathrm{X}$. By definition, $\operatorname{cSAR}(\mathrm{X})$ is a sum of atomic charges at all atoms of the substituent and the ipso carbon atom [7]. This descriptor correlates well with substituent constants [7-10]. It is important to stress that the $\operatorname{cSAR}(\mathrm{X})$ approach realized by the use of different atomic charge schemes leads to the results which are, as a rule, mutually well correlated [11]. The more negative is its value, the more electron attracting is a substituent, and vice versa for electron-donating properties - the more positive $\operatorname{cSAR}(\mathrm{X})$, the more electron donating is the substituent. Moreover, the cSAR approach can be applied to both, the varying substituents, [as $\operatorname{cSAR}(\mathrm{X})]$, as well as to the reaction site (or a fixed functional group in the series $\mathrm{X}-\mathrm{R}-\mathrm{Y}),[\mathrm{cSAR}(\mathrm{Y})]$, and allows to estimate the regression line $\operatorname{cSAR}(\mathrm{Y})$ vs. $\operatorname{cSAR}(\mathrm{X})$. The slope of this regression describes the strength of interactions between $\mathrm{X}$ and $\mathrm{Y}[9,10]$. It was also shown that changes in geometry of the components of the functional group $\mathrm{Y}$ correlate well with $\operatorname{cSAR}(\mathrm{Y})$ [12] and hence correlate also with $\operatorname{cSAR}(\mathrm{X})$ that was documented for aniline [10], nitrobenzene [13], and benzoic acid [14] substituted derivatives.
Another possibility of the application of quantum chemical computations for the modeling of SE are isodesmic or homodesmotic reactions $[6,15]$. They can be used to obtain the SESE characteristic. This approach allows to determine, in an energetic scale, the nature of the interaction between substituents in disubstituted systems. It was documented that the SESE characteristic correlates well with classical substituent constants $[9,10]$. SESE is a descriptor of substituent electron donating/attracting properties and takes into account all interactions in the X-R-Y system.

Chemical compounds with hydroxy and phenoxide groups are of great interest in many fields of chemistry, biochemistry, and related fields of science and technology [16-18]. Hydroxy group is also a part of carboxyl group, and hence, it is of great importance for interactions in which proteins participate. This implies its high importance in all branches of life science and medical chemistry $[19,20]$. Many nucleic bases may exist in tautomeric form with $\mathrm{OH}$ group as their important component $[16,21,22]$.

Since $\mathrm{OH} / \mathrm{O}^{-}$groups are present in so many important compounds, a systematic study of their electron donating/ attracting properties can give a possibility to get a wider and deeper knowledge on their influence on molecular systems containing them. Additionally, it is important to stress that acid base equilibria $\mathrm{PhOH} / \mathrm{PhO}^{-}$constitutes the reference reaction for estimating $\sigma_{\mathrm{p}}{ }^{-}$substituent constants which are necessary to describe reactions with negatively charged reaction sites [23].

The application of the abovementioned quantum chemicalbased models of substituent effect to series of meta-substituted and para-substituted derivatives of phenol and phenolate allows to recognize the changeability of electron donating/ attracting properties of $\mathrm{OH}$ and $\mathrm{O}^{-}$groups resulted from an action of various substituents. A comparison of the SE characteristics based on physical models with the traditional SC can enables a presentation of data expressed in SESE or cSAR in the scale of well-known $\sigma$ constants. Finally, since both functional groups, $\mathrm{OH}$ and $\mathrm{O}^{-}$, are known as strongly interacting with moieties to which they are attached, we intend to estimate their reverse substituent effects. This means to evaluate the impact of these groups on the electron donating/ attracting properties of substituents attached in meta and para positions in phenol and phenolate derivatives.

\section{Methodology}

The molecular geometries of phenol and phenolate as well as their monosubstituted derivatives $\left(\mathrm{X}=\mathrm{NO}, \mathrm{NO}_{2}, \mathrm{CN}\right.$, $\mathrm{COCl}, \mathrm{CF}_{3}, \mathrm{COMe}, \mathrm{COOH}, \mathrm{CHO}, \mathrm{CONH}_{2}, \mathrm{Cl}, \mathrm{F}, \mathrm{H}, \mathrm{Me}$, $\mathrm{OMe}, \mathrm{OH}, \mathrm{NH}_{2}$, and $\mathrm{NMe}_{2}$ ) have been fully optimized at the B3LYP $[24,25]$ level of theory and $6-311++\mathrm{G}^{* *}$ basis set [26] with the GAUSSIAN09 program [27]; for 
branched substituents, several conformations have been taken into account to find the global minimum energy structure. Each stationary point was then characterized at the same level of theory by computing the vibrational frequencies within the harmonic approximation to ensure that the resulting structures were the minima with no imaginary frequencies. Moreover, their effective wavefunctions at the same level of theory have been used to characterize topological properties of the electronic charge density.

For each system studied, the energy-based descriptor SESE has been evaluated using a homodesmotic reaction which is based on total energies of optimized systems $[15,28-30]$ (eq. (1)):

$$
\mathrm{X}-\mathbf{R}-\mathrm{Y}+\mathbf{R} \rightarrow \mathbf{R}-\mathrm{X}+\mathbf{R}-\mathrm{Y}
$$

By using this model, the energetic effect of the interaction between a substituent $(\mathrm{X})$ and a reaction site $(\mathrm{Y})$, which is $\mathrm{OH}$ or $\mathrm{O}^{-}$group in this work ( $\mathrm{R}$ denotes the benzene ring), could be described. The greater stabilization energy due to the substituent effect leads to the greater SESE value and indicates the stronger stabilization in disubstituted system (see eq. (2)).

$$
\mathrm{SESE}=\mathrm{E}(\mathbf{R}-\mathrm{X})+(\mathbf{R}-\mathrm{Y})-\mathrm{E}(\mathrm{X}-\mathbf{R}-\mathrm{Y})-\mathrm{E}(\mathbf{R})
$$

Another parameter used to describe the substituent effect is cSAR $(\mathrm{X})$ - a substituent active region parameter $[7,31]$ which can be calculated according to eq. (3)

$\operatorname{cSAR}(\mathrm{X})=q(\mathrm{X})+q\left(\mathrm{C}_{\mathrm{ipso}}\right)$

where $q(\mathrm{X})$ and $q\left(\mathrm{C}_{i p s o}\right)$ are charges of atoms belonging to the substituent $\mathrm{X}$ and the ipso carbon atom to which the substituent is attached, respectively.

An assessment of atomic charges has been performed through three different methods: (a) Hirshfeld [32], (b) Bader [33], and (c) Weinhold [34]. The AIM2000 package [35] has been employed for calculation of Bader's AIM atomic charges. Weinhold's natural population analysis (NPA) has been performed with NBO 6.0 program [36].

The NBO 6.0 program has been also used for calculating a $p$ EDA descriptor (eq. 4) [37] for the transmitting moiety (R)the benzene ring. The $\pi$-effect is defined by the sum of occupancies of $p_{\mathrm{z}}$ orbitals of all $\mathrm{C}$ atoms in the ring (located in the $x y$ plane) contributing to the benzene $\pi$-electron system.

$p \mathrm{EDA}=\sum_{i=1}^{6} \pi_{\mathbf{R}}^{i}-\sum_{i=1}^{6} \pi_{\mathrm{C} 6 \mathrm{H} 6}^{i}$

where $\pi^{i}$ denotes sums of occupancies of all atomic orbitals of the $i$ th $\mathrm{C}$-atom in the benzene ring contributing to the valence $\pi$-molecular orbitals.

To characterize an effect of the substituent on the transmitting moiety, a geometry-based aromaticity index Harmonic Oscillator Model of Aromaticity (HOMA) $[38,39]$ has been used. It is defined as

$\mathrm{HOMA}=1-\frac{\alpha}{n} \sum\left(d_{o p t}-d_{i}\right)^{2}$

where $n$ is the number of bonds taken into account; $\alpha$ is a normalization factor which is for $\mathrm{CC}$ bond fixed to 257.7 to give HOMA $=0$ for a model nonaromatic system and 1 for the system with all bonds equal to the optimal value $\left(d_{\mathrm{opt}}=1.388 \AA\right)$, and $d_{i}$ stands for a running bond length.

Additionally, the GIAO/B3LYP/6-311++G** method [40] has been used to calculate NMR shielding and also NICS at the geometric center of a ring defined as $\operatorname{NICS}(0)$, at $1 \AA$ above the center denoted as NICS(1) as well as its component corresponding to the principal axis perpendicular to the ring plane denoted as NICS(1)zz [41-43].

\section{Results and Discussion}

The obtained results and subsequent analysis are presented in subsections devoted to: (i) quantitative characteristics of the substituent effect and their mutual interrelations, (ii) the classical substituent effect - the influence of substituents $X$ on the properties of $\mathrm{OH}$ and $\mathrm{O}^{-}$groups, (iii) the influence of a substituent on the transmitting moiety properties, and (iv) the reverse substituent effect, i.e., how the electron attracting/ donating properties of the substituent $\mathrm{X}$ depend on the nature of a moiety to which it is attached. The values of all obtained characteristics are gathered in Tables $1 \mathrm{~S}$ and $2 \mathrm{~S}$ for phenol and phenolate derivatives, respectively.

\section{Quantitative characteristics of the substituent effect}

In studies of substituent effects in meta-substituted and parasubstituted phenol and phenolate derivatives, it is reasonable to look firstly at the mutual relations between the substituent effect descriptors. In this work, we have used: the traditional Hammett's substituent constant, cSAR, and SESE descriptors. To get a deeper insight, the mutual interrelations are shown for three methods of the atomic charge assessment: Hirshfeld, Weinhold (NBO), and Bader (AIM). The statistics of the linear regressions are given in Tables 2, 3S, and 4S.

A few results are worth mentioning. Firstly, consider relations of the data independent of the atomic charge assessment method - the case of SESE vs. Hammett's substituent constants. It is important to stress that both Hammett-like substituent constants and SESE descriptors take into account all interactions in the substituted systems. For para-substituted phenols and phenolates and for meta-substituted phenolates, the correlations are excellent as shown in Fig. 1. This is not a case of meta-substituted phenols for which a very small variability of SESE values has been found. It is also noted 
Table 2. Interrelations between characteristics of substituents in phenol and phenolate anion derivatives.

\begin{tabular}{|c|c|c|c|c|c|c|c|c|}
\hline & $R^{2}$ & $a$ & $b$ & $a_{\mathrm{p}} / a_{\mathrm{m}}$ & $\Delta 1$ & $\Delta 1_{p} / \Delta 1_{m}$ & $\Delta 2$ & $\Delta 2_{p} / \Delta 2_{m}$ \\
\hline & \multicolumn{3}{|c|}{$\mathrm{SESE}=a \cdot \sigma+b$} & & SESE & & $\sigma$ & \\
\hline \multirow[t]{2}{*}{$m$} & 0.218 & -0.515 & 0.323 & -5.19 & 0.84 & 5.02 & 0.87 & 2.00 \\
\hline & 0.942 & 21.361 & 0.916 & 1.04 & 17.05 & 1.96 & 0.87 & 2.00 \\
\hline \multirow[t]{2}{*}{$p$} & 0.847 & 2.671 & -0.427 & & 4.22 & & 1.74 & \\
\hline & 0.864 & 22.131 & 5.977 & & 33.50 & & 1.74 & \\
\hline$p^{*}$ & 0.860 & 2.160 & -0.954 & & 4.22 & & 2.00 & \\
\hline$p^{*}$ & 0.971 & 18.818 & 1.169 & & 33.50 & & 2.00 & \\
\hline \multirow[t]{3}{*}{$m+p$} & 0.572 & 1.972 & -0.335 & & & & & \\
\hline & 0.804 & 21.196 & 3.558 & & & & & \\
\hline & \multicolumn{4}{|c|}{$\operatorname{cSAR}(\mathrm{X})_{\mathrm{Hirsh}}=a \cdot \sigma+b$} & \multicolumn{2}{|l|}{$\operatorname{cSAR}(\mathrm{X})_{\text {Hirsh }}$} & $\sigma$ & \\
\hline \multirow[t]{2}{*}{$m$} & 0.870 & -0.306 & 0.055 & 0.55 & 0.28 & 0.93 & 0.87 & 2.00 \\
\hline & 0.817 & -0.299 & -0.092 & 0.74 & 0.26 & 1.31 & 0.87 & 2.00 \\
\hline \multirow[t]{2}{*}{$p$} & 0.961 & -0.169 & -0.030 & & 0.26 & & 1.74 & \\
\hline & 0.788 & -0.220 & -0.237 & & 0.34 & & 1.74 & \\
\hline$p^{*}$ & 0.847 & -0.128 & -0.001 & & 0.26 & & 2.00 & \\
\hline$p^{*}$ & 0.960 & -0.194 & -0.185 & & 0.34 & & 2.00 & \\
\hline \multirow[t]{3}{*}{$m+p$} & 0.771 & -0.192 & -0.002 & & & & & \\
\hline & 0.549 & -0.219 & -0.176 & & & & & \\
\hline & \multicolumn{4}{|c|}{$\operatorname{cSAR}(\mathrm{X})_{\mathrm{Hirsh}}=a \cdot \mathrm{SESE}+b$} & \multicolumn{2}{|l|}{$\operatorname{cSAR}(\mathrm{X})_{\text {Hirsh }}$} & SESE & \\
\hline \multirow[t]{2}{*}{$m$} & 0.219 & 0.139 & -0.056 & -0.40 & 0.28 & 0.93 & 0.84 & 5.02 \\
\hline & 0.911 & -0.014 & -0.077 & 0.71 & 0.26 & 1.31 & 17.05 & 1.96 \\
\hline \multirow[t]{2}{*}{$p$} & 0.846 & -0.055 & -0.058 & & 0.26 & & 4.22 & \\
\hline & 0.983 & -0.010 & -0.173 & & 0.34 & & 33.50 & \\
\hline \multirow[t]{2}{*}{$m+p$} & 0.309 & -0.047 & -0.041 & & & & & \\
\hline & 0.875 & -0.012 & -0.128 & & & & & \\
\hline
\end{tabular}

In the equation $f(\mathrm{x})=a \cdot \mathrm{x}+b, \Delta 1$ and $\Delta 2$ denote ranges of variability $f(\mathrm{x})$ and $\mathrm{x}$, respectively. Data for phenolate anion derivatives are in bold (cSAR data related to Hirshfeld charge)

*equation with $\sigma_{\mathrm{p}}{ }^{-}$constants

that the use of $\sigma_{\mathrm{p}}{ }^{-}$for para series leads to better correlations than the application of the original Hammett $\sigma_{\mathrm{p}}$ constants, particularly in the case of phenolates.

In two other cases, cSAR(X) vs. $\sigma$ and cSAR(X) vs. SESE, regression lines are more acceptable for para-substituted than for the meta-substituted derivatives. As a rule, these relationships reveal weaker correlations. This may result from the fact that $\mathrm{cSAR}(\mathrm{X})$ describes rather local electron properties of substituents, whereas both, the Hammett substituent constants and SESE, take into account all intramolecular interactions in a substituted molecule.

Additionally, both abovementioned relationships depend on the method of atomic charge assessment (see Tables 2, $3 \mathrm{~S}$, and $4 \mathrm{~S}$ and Fig. 1S). To estimate these dependences, let us consider regression lines for meta and para derivatives of phenols and phenolates in the case of $\operatorname{cSAR}(\mathrm{X})$ vs. original Hammett $\sigma$ constant relations. The determination coefficients are the best for Hirshfeld estimation of charges (0.788-0.961), followed by AIM (0.726-0.940) and then NBO (0.648-0.867). Figure 2 presents comparison of $\mathrm{cSAR}(\mathrm{X})$ vs. $\sigma$ relations for meta-substituted and para- substituted species and for Hirshfeld charge of atoms assessment. It is important to note the almost identical sensitivity of the substituent effect in meta-substituted phenol and phenolate derivatives: the slopes are equal to -0.306 and -0.299 , respectively, indicating a similar nature of interactions in both series. Contrary to this, values of the slopes for para-substituted species are different: -0.169 and 0.220 , respectively, indicating different kinds of intramolecular interactions in these series. The application of $\sigma_{\mathrm{p}}{ }^{-}$ instead of $\sigma_{\mathrm{p}}$ in the latter case and different charge assessments leads to qualitatively similar results (Fig. 1S). In further discussion, the Hirshfeld assessment of atomic charges will be used.

The dependences of cSAR(X) on SESE for para-substituted phenol and phenolate derivatives and for meta derivatives of phenolates are presented in Fig. 3. As expected, in all three cases, increase of SESE is associated with an increase of a negative charge at the substituent which is in line with its increasing electron-attracting properties.

However, since $\mathrm{OH}$ group in meta position has electronaccepting properties (Table 1) the situation in the case of meta- 
a

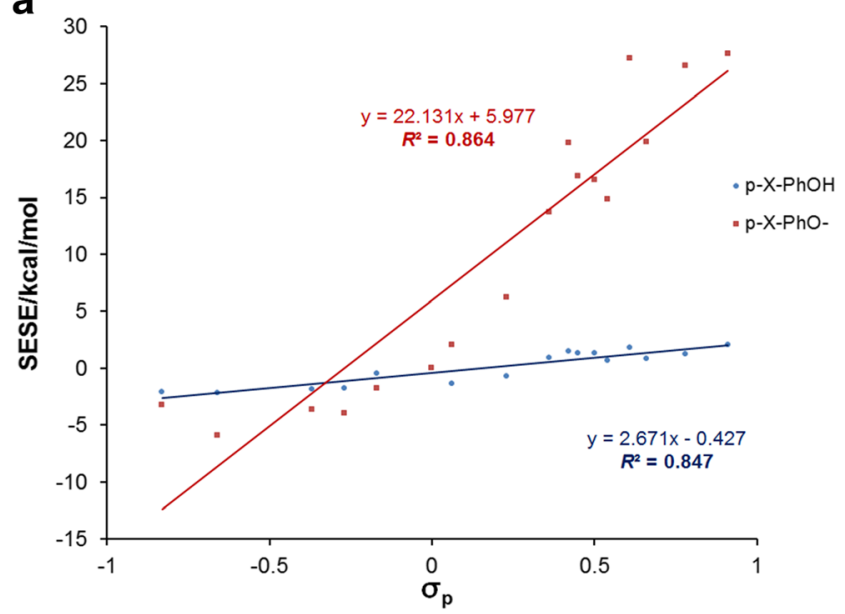

b

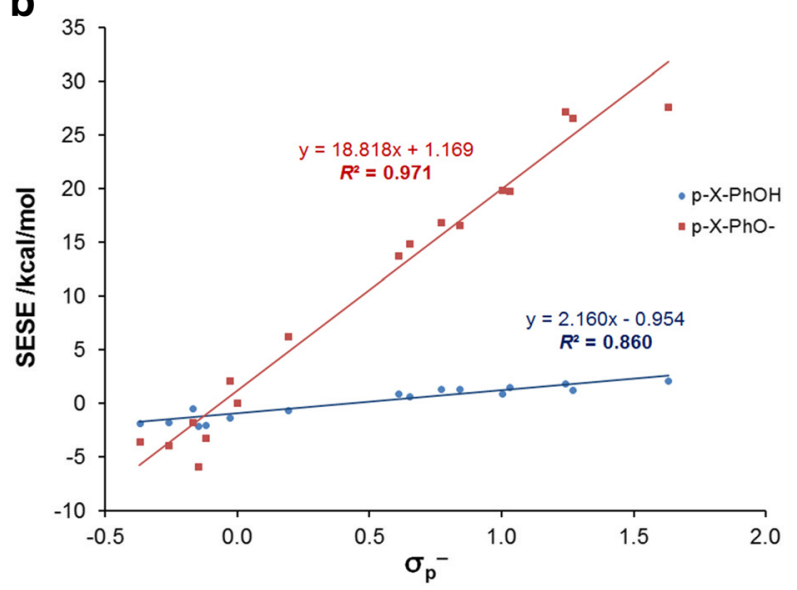

C

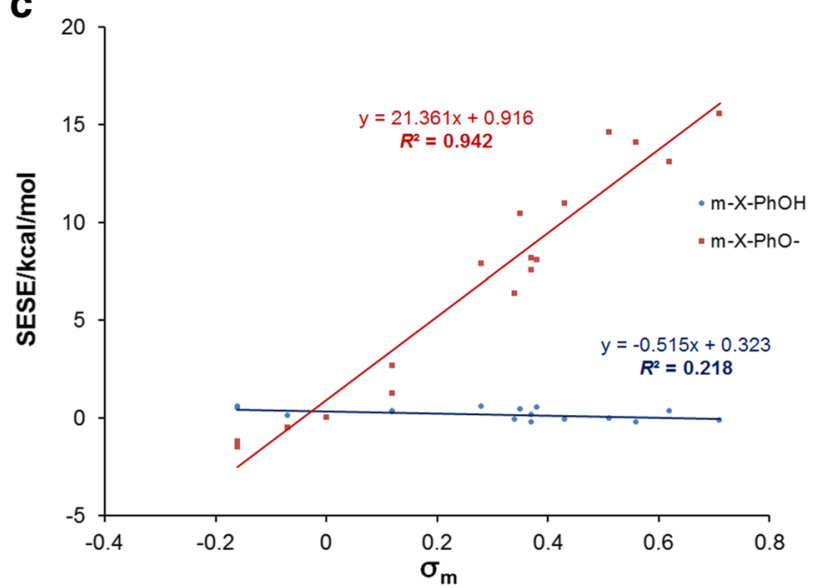

Fig. 1. Dependences of SESE on (a) $\sigma_{\mathrm{p}}$ and (b) $\sigma_{\mathrm{p}}{ }^{-}$for para and (c) on $\sigma_{\mathrm{m}}$ for meta in substituted phenol and phenolate derivatives.

substituted phenol derivatives is quite different. The dependence of $\operatorname{cSAR}(\mathrm{X})$ on SESE is presented in Fig. 4 and suggests a division of substituents into two groups: (i) electrondonating substituents with negative resonance substituent constants $R \leq 0.0$ ( $R$ taken from [3]) and (ii) the remaining substituents $(R>0.0)$. In contrast to the relations shown in Fig. 3 for both groups, positive values of the slopes and almost a

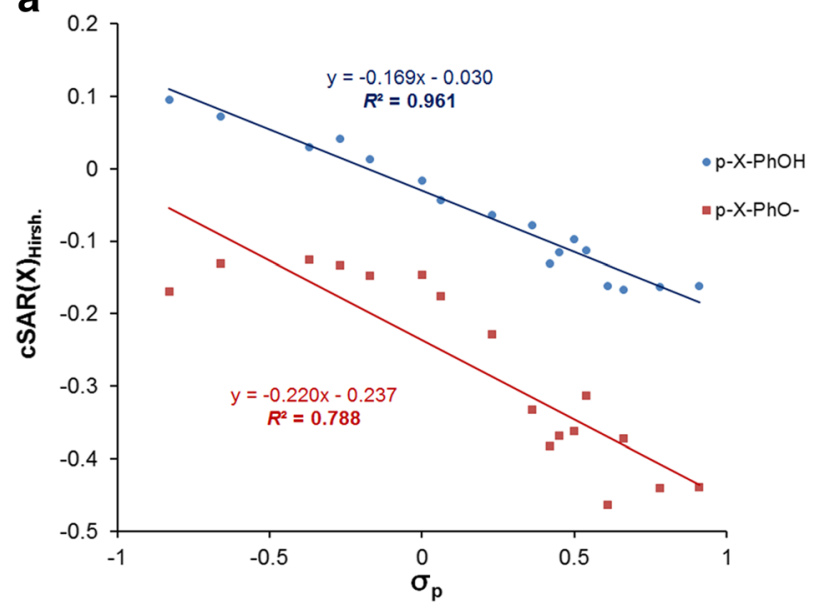

b

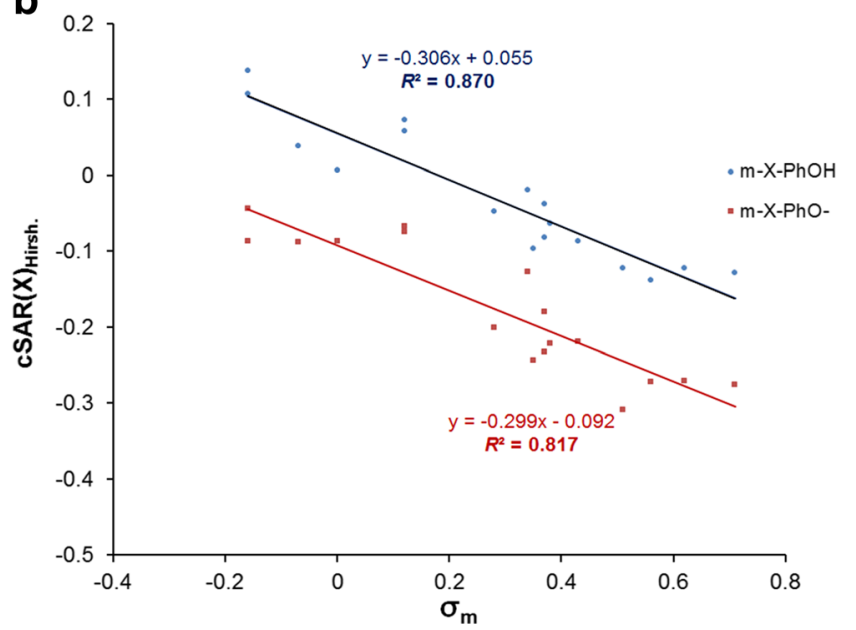

Fig. 2. Relations between $\operatorname{cSAR}(\mathrm{X})$ and $\sigma_{\mathrm{p}}$ and $\sigma_{\mathrm{m}}$ for (a) parasubstituted and (b) meta-substituted phenols and phenolates obtained for the Hirshfeld charge assessment.

the same ranges of SESE values are observed. Therefore, a decrease of $\operatorname{cSAR}(\mathrm{X})$ (an increase of the negative charge) is associated with a decrease in stability of the systems in question (a decrease of SESE values), but two equations are needed to describe these relationships.

The upper line with $R^{2}=0.982$ indicates that an increase of $\operatorname{cSAR}(\mathrm{X})$ (denoting an increase of electron-donating properties of the substituent) is strongly associated with an increase in stabilization of di-substituted species. This stabilization can be explained by an electron-attracting property of meta position in phenol (Table 1), and hence, stronger intramolecular interactions are observed with increasing electron-donating ability of substituents. A similar trend is observed (but with a worse determination coefficient) for electron-attracting substituents presented by the lower line in Fig. 4.

The above conclusion allows to assume that the substituent effect mechanism in meta position is different for electronattracting and electron-donating substituents. To check this statement, the relation between substituent field/inductive constant $(F)$ and Hammett's $\sigma_{\mathrm{m}}$ is shown in Fig. 5. It is known that 

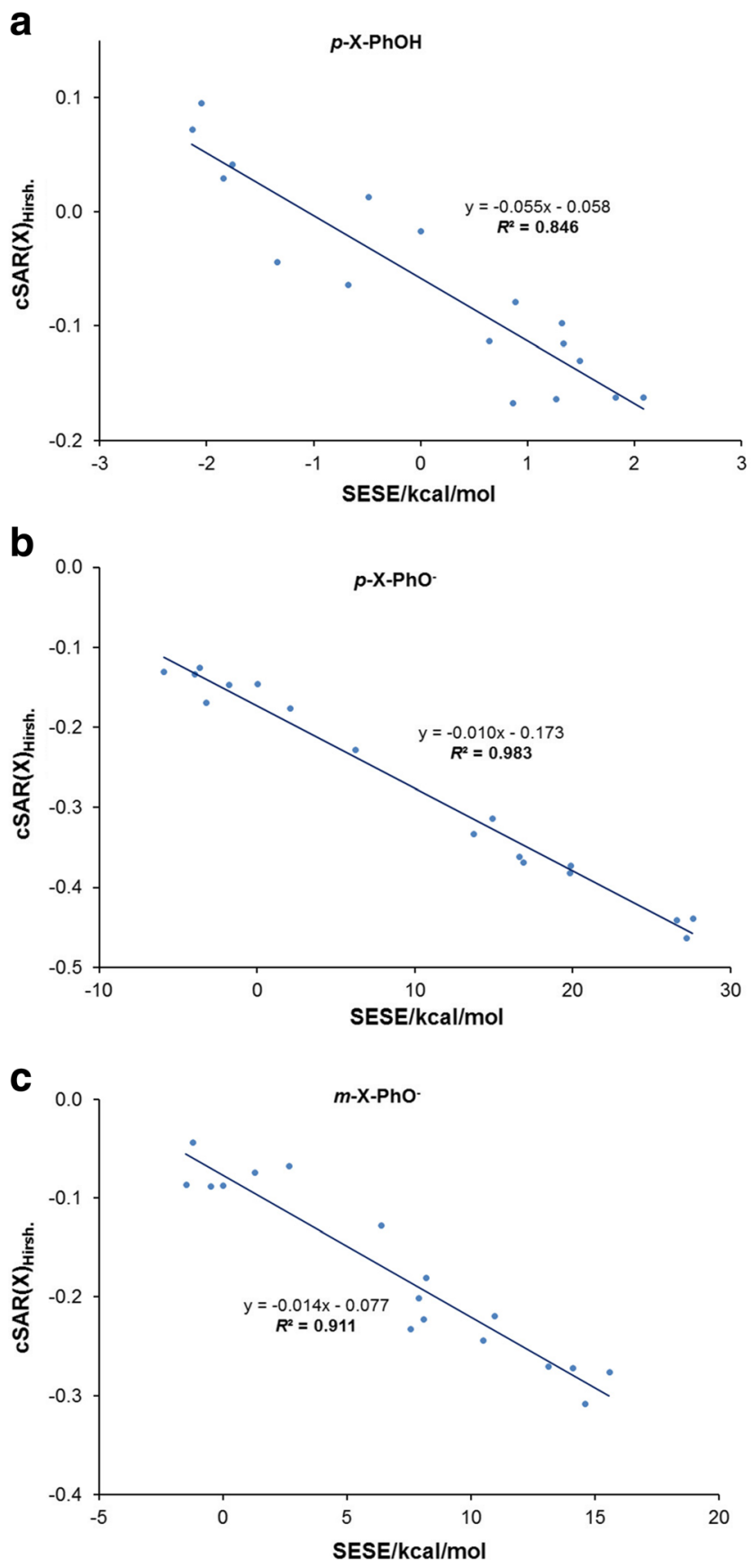

Fig. 3. Dependences of cSAR $(\mathrm{X})_{\text {Hirsh }}$ on SESE for para-substituted phenol (a) and phenolate (b) and meta-substituted phenolate (c) series.

interactions described by $\sigma_{\mathrm{m}}$ consist of two main components: the resonance effect and the inductive/field one [44, 45]. Data presented in Fig. 5 suggest that there are two substituent groups for which the regression lines are separated, indicating different dependences of $F$ on $\sigma_{\mathrm{m}}$. It indicates different contributions of the aforementioned components for interactions described by $\sigma_{\mathrm{m}}$, therefore, confirms the different mechanism of interactions for meta position. Note that the same kind of separation is observed for electron-attracting and electron-donating substituents in Fig. 4.

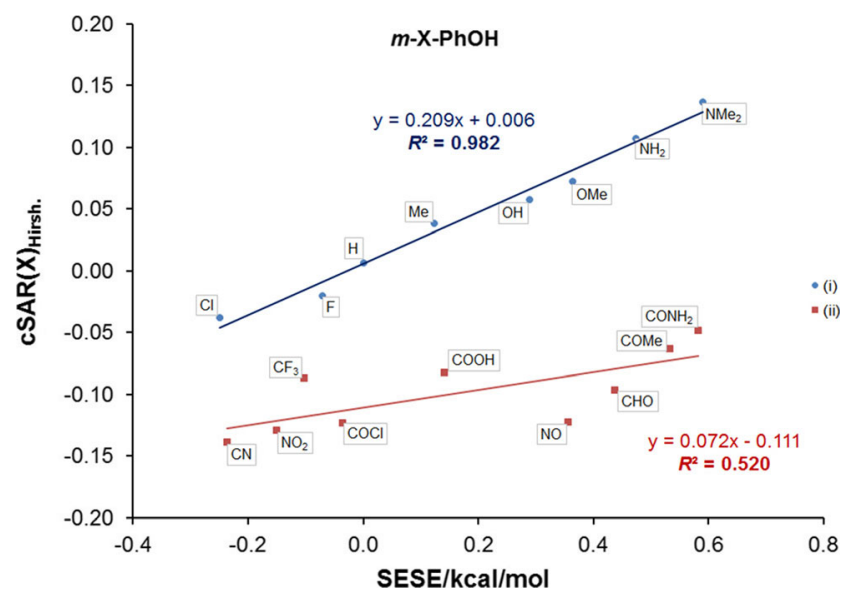

Fig. 4. Regression of $\mathrm{cSAR}(\mathrm{X})_{\mathrm{Hirsh}}$ vs. SESE for meta-X-PH-OH derivatives.

\section{Classical substituent effect}

Consider now a traditional Hammett scheme of analyses applying cSAR descriptors for substituents and for the "reaction site" (i.e., $\mathrm{OH}$ and $\mathrm{O}^{-}$groups). Figure 6 shows dependences of $\operatorname{cSAR}(\mathrm{OH})$ and $\operatorname{cSAR}\left(\mathrm{O}^{-}\right)$on $\operatorname{cSAR}(\mathrm{X})$.

The classical Hammett's approach deals with relations between chemical property of a reaction site $\mathrm{Y}$ and substituent constants. Here, we present another view of this kind of relation showing dependences of $\operatorname{cSAR}(\mathrm{Y})$ on $\operatorname{cSAR}(\mathrm{X})$, where $\mathrm{Y}=\mathrm{OH}$ or $\mathrm{O}^{-}$. In the presented dependences in Fig. 6, both variables are in the same scale of magnitude, and hence, comparisons of slopes are justified. For para-substituted species, determination coefficients are very high $\left(R^{2}>0.971\right)$ and the slope for phenolate data is higher (as the absolute value) than for the phenols, -0.376 and -0.337 , respectively, indicating stronger interactions between substituents and the reaction site $\mathrm{Y}$ in phenolates. The opposite situation is encountered for meta derivatives. Determination coefficients are lower (0.675 and 0.909 , respectively), but values of the slopes

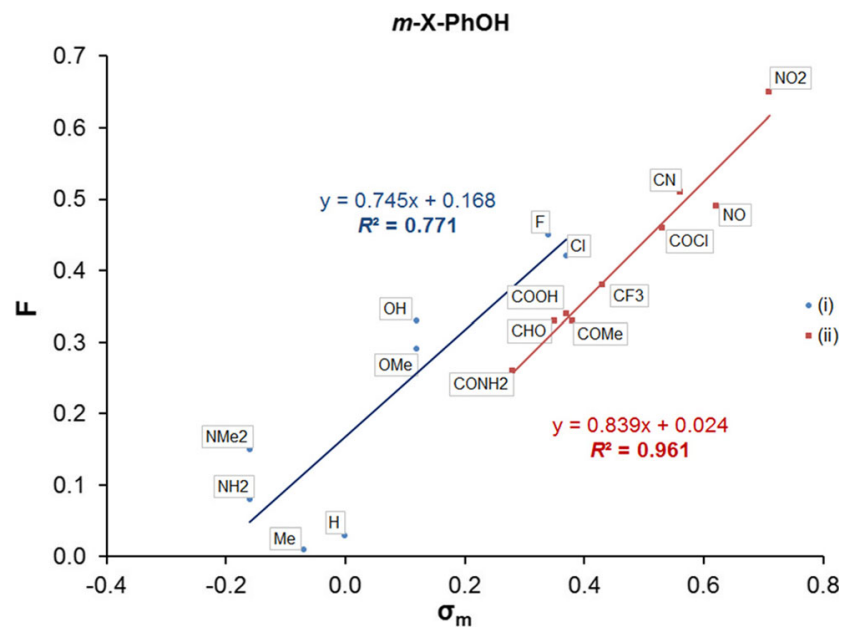

Fig. 5. Dependence of field/inductive constant $F$ on $\sigma_{\mathrm{m}}$ for (i) and (ii) groups of substituent (see text; ED and EA substituents, respectively). 


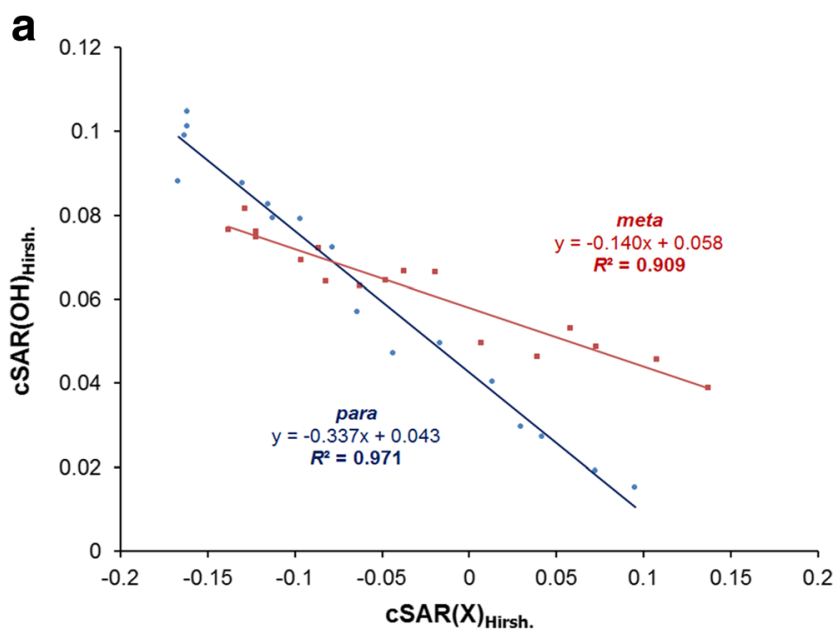

b

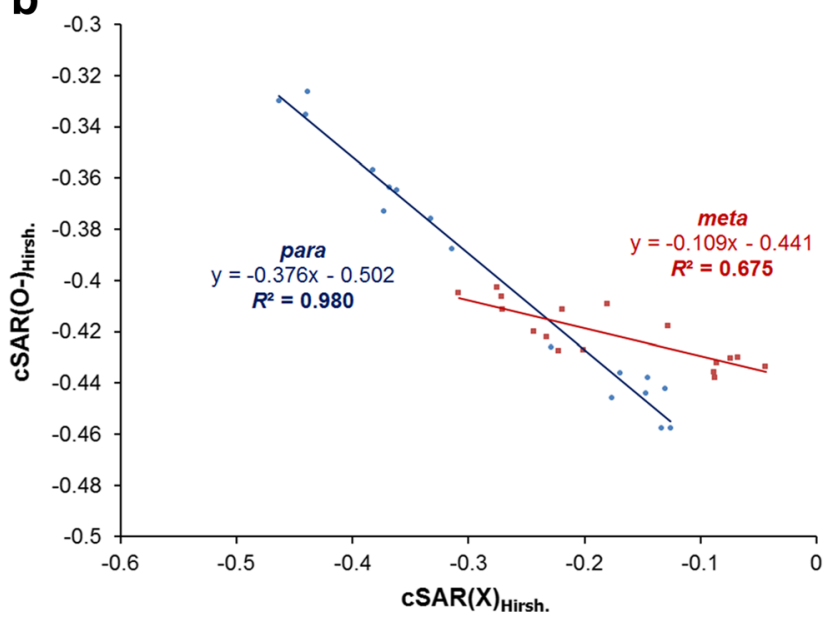

Fig. 6. Dependences of $\operatorname{cSAR}(\mathrm{Y})$ on $\operatorname{cSAR}(\mathrm{X})$, for $\mathrm{Y}=\mathrm{OH}(\mathbf{a})$ or $\mathrm{O}^{-}(\mathbf{b})$ in meta-substituted and para-substituted series.

suggest a better communication for phenol derivatives than for the phenolates, with the slopes equal to -0.140 and -0.109 , respectively.

\section{Substituent effects on transmitting moiety properties}

To characterize changes in $\pi$-electron delocalization of the benzene ring (the transmitting moiety of the studied systems), HOMA [38, 39], NICS [41-43], and $p$ EDA [37] parameters were used.

In accordance with the earlier studies [46] in the case of phenol derivatives, HOMA and NICSs present a very low variability and no clear dependences on SE characteristics are observed. Nevertheless, the ranges of the variability of HOMA and NICS aromaticity characteristics are dramatically greater for para-substituted phenolates than for phenols $(\sim 10$ and 2 times, respectively). Scatter plots of these indices vs. SESE or cSAR(X) for phenolates have acceptable determination coefficients $\left(R^{2}>0.81\right.$, Figs. $2 \mathrm{~S}$ and $\left.3 \mathrm{~S}\right)$ and document an increase of aromaticity with increasing $\operatorname{cSAR}(X)$ values (Fig. 2S). For meta-substituted phenolates, the variability of
HOMA and NICS is very low and no clear dependences on substituent characteristics are observed.

It has been already shown that changes in the $\pi$-electron structure may be well described by $p \mathrm{EDA}[9,37,47]$. In the case of strong substituent effect, as in para-substituted phenolate derivatives, $p$ EDA is well correlated with HOMA as shown in Fig. 7. The increase of $\pi$-electron population in the ring described by $p$ EDA values is associated with an increase of aromaticity indicated by HOMA. Low range of variation of HOMA for meta derivatives does not allow for the strong conclusion; nevertheless, a reverse picture might be found.

\section{Reverse substituent effect}

A nonequivalent character of interactions in meta-substituted and para-substituted phenols and phenolates is also well illustrated by relations between $\mathrm{cSAR}(\mathrm{X})$ values for para and meta series. As presented in Fig. 8 for phenol derivatives, the slope close to 1.0 indicates a highly similar reverse substituent effect from meta and para positions. However, this is not the case for phenolate series, where the reverse substituent effect for metasubstituted derivatives is 0.687 times weaker than for the para ones. A very similar result is found for the regression of differences in energy between phenols and appropriate phenolates, $\left[\mathrm{E}(\mathrm{X}-\mathrm{Ph}-\mathrm{OH})-\mathrm{E}\left(\mathrm{X}-\mathrm{Ph}-\mathrm{O}^{-}\right)\right]$. This is shown in Fig. 9, where the slope is 0.525 . Undoubtedly, this indicates a different nature of the substituent effect from para and meta positions.

One more illustration of the reverse substituent effect is provided by a comparison of $\operatorname{cSAR}(\mathrm{X})$ values in phenol and phenolate series with the values of $\operatorname{cSAR}(\mathrm{X})$ for monosubstituted benzene derivatives (Fig. 10). In all cases, $R^{2}>0.89$ indicates reliable results. For phenol derivatives (Fig. 10a), a minor difference between slopes for meta-substituted and para-substituted systems is observed - it means that the reverse substituent effects are very similar. The difference appears for phenolate series (Fig. 10b). The observed reverse substituent effect for both meta and para derivatives is greater than in the phenol series (slopes greater than 1.0). Additionally, the obtained slope for the para phenolates is larger than that for the meta one. The above presented analyses are understandable since $\mathrm{O}^{-}$group undoubtedly affects strongly electron donating/attracting properties of substituents.

The reverse substituent effect is the most clearly presented by numerical data from Table 3. Comparisons of $\operatorname{cSAR}(\mathrm{X})$ for a particular substituent are facilitated by values of $\Delta 1$ and $\Delta 2$ which inform how much cSAR(X) in meta and para positions in phenol and phenolate series, respectively, differ.

In the case of the phenol series for particular substituents, these differences account for 11-15\% of the cSAR(X) variability range, $\Delta$. For phenolates, these differences are significantly greater and vary from 23 to $53 \%$ of $\Delta$. When all studied series are taken together into account then the range of the $\operatorname{cSAR}(\mathrm{X})$ variation is 0.600 , whereas the greatest value of 


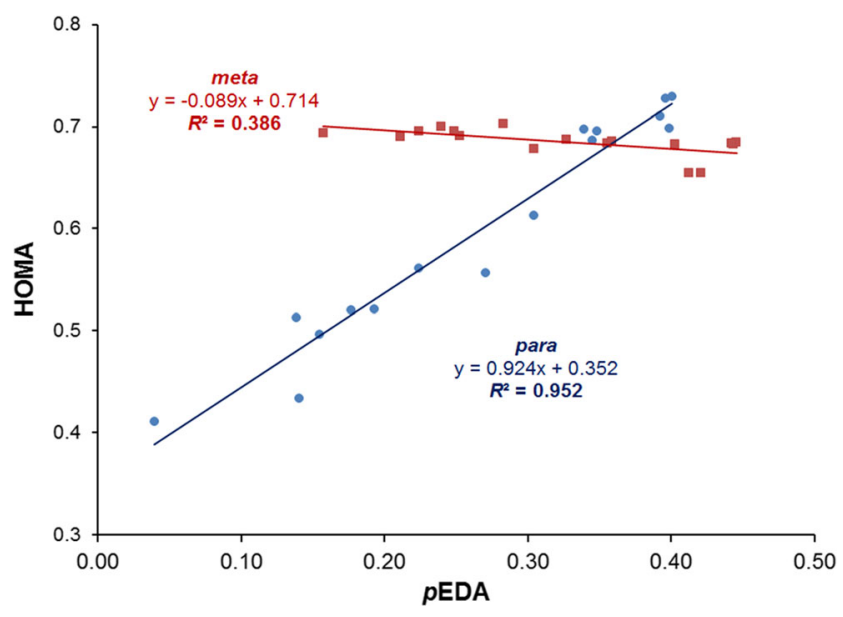

Fig. 7. Dependences of HOMA on $p$ EDA in meta-substituted and parasubstituted phenolates.

$\Delta=0.340$, which constitutes $56.6 \%$ of the total variability of $\operatorname{cSAR}(\mathrm{X})$. This is a very good illustration how dramatically electron donating/attracting properties of substituents can be modified depending on the moiety to which they are attached.

One more very important meaning of $\Delta$ values is that they allow to quantify the range of a potential variability in electron attracting/donating properties of any substituent, as shown in Table 3. Let us illustrate this in practice. The substituents with the greatest ability for changing their electron attracting/ donating properties are: $\mathrm{COCl}, \mathrm{NO}, \mathrm{NO}_{2}$, and $\mathrm{NMe}_{2}$ with $\Delta>0.300$, whereas $\mathrm{H}, \mathrm{F}, \mathrm{OH}$, and $\mathrm{Me}$ (with $\Delta<0.190$ ) may be indicated as the substituents with a weaker ability for changing their electronic properties. This information may be particularly important in cases of not wellrecognized electronic properties (electron attracting or donating) of the moiety to which the substituent is to be attached. The high value of $\Delta$ for $\mathrm{NMe}_{2}$ substituent needs a comment. Firstly, let us note that $\Delta 1$ has the highest value for $\mathrm{NMe}_{2}$ (0.042), even higher than for a strongly electron-attracting NO group (0.040). This is due to the electron-attracting

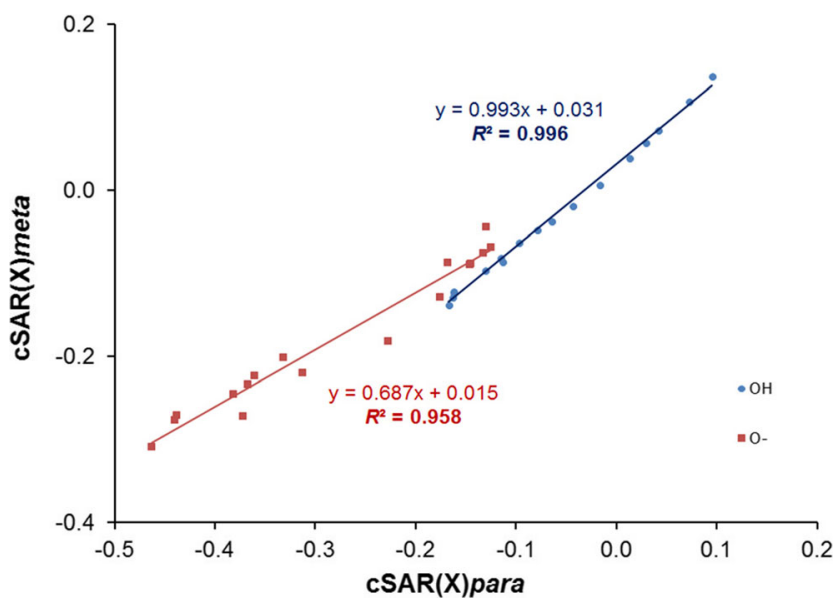

Fig. 8. Dependences of $\operatorname{cSAR}(\mathrm{X})_{\text {Hirsh }}$ of meta derivatives on the para ones for phenols and phenolates.

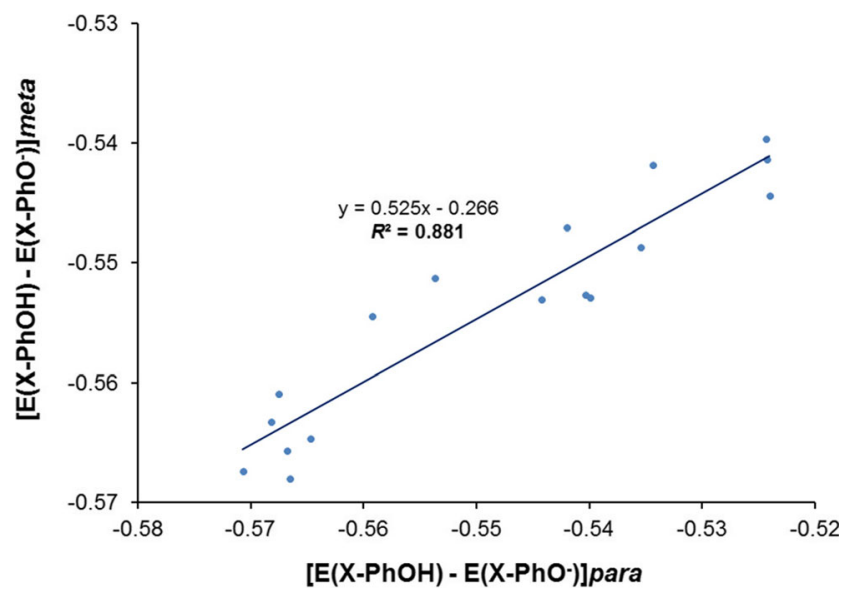

Fig. 9. Dependence of $\left[\mathrm{E}(\mathrm{X}-\mathrm{Ph}-\mathrm{OH})-\mathrm{E}\left(\mathrm{X}-\mathrm{Ph}-\mathrm{O}^{-}\right)\right]$meta values on $\left[\mathrm{E}(\mathrm{X}-\mathrm{Ph}-\mathrm{OH})-\mathrm{E}\left(\mathrm{X}-\mathrm{Ph}-\mathrm{O}^{-}\right)\right]$para for studied derivatives.

property of meta position in phenol, as shown in Table 1 . This is a reason why $\boldsymbol{\Delta}$ for $\mathrm{NMe}_{2}$ substituent is so large. One more information comes from the comparison of ranges of $\operatorname{cSAR}(\mathrm{X})$ values in the dependence on the kind and the position of $\mathrm{Y}\left(\mathrm{OH}\right.$ or $\left.\mathrm{O}^{-}\right)$. Usually, it is accepted that
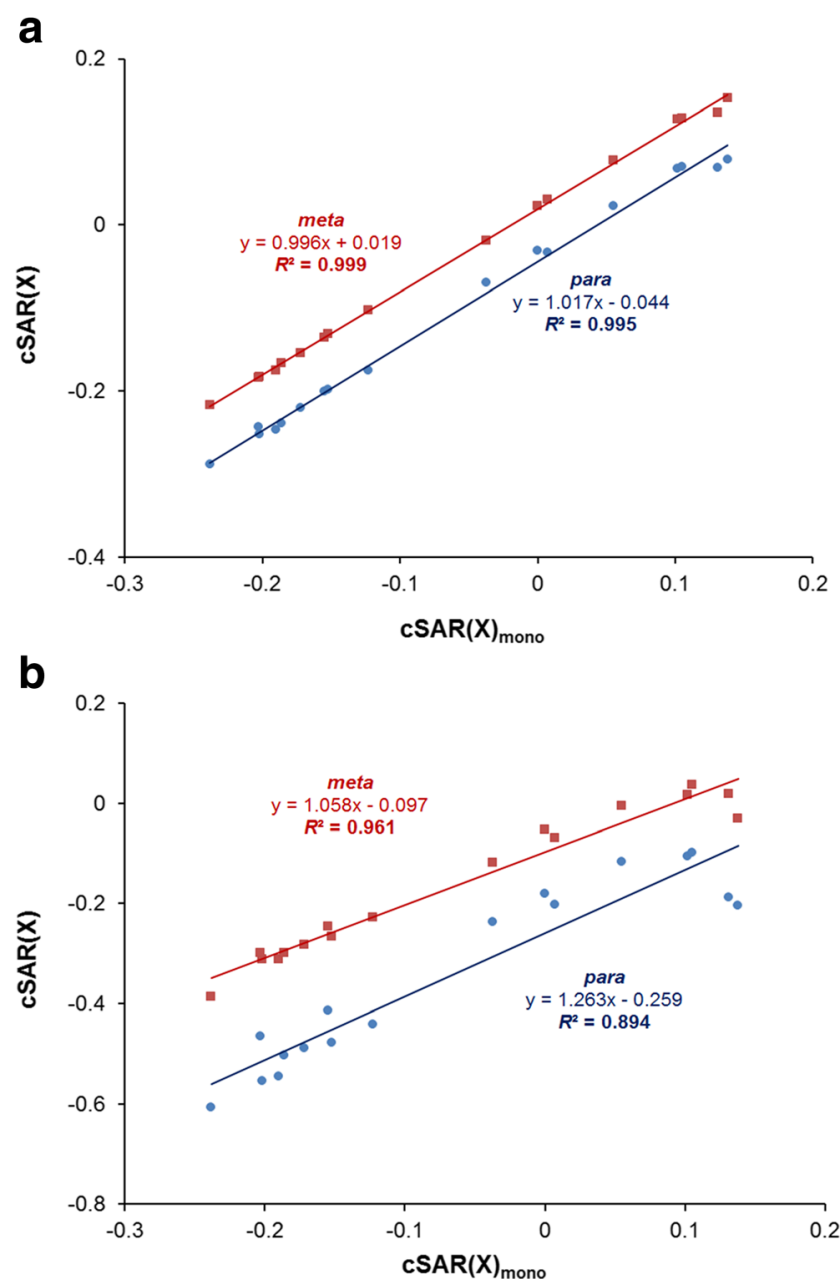

Fig. 10. Dependences of $\operatorname{cSAR}(\mathrm{X})_{\mathrm{NBO}}$ for phenol (a) and phenolate (b) derivatives on $\mathrm{CSAR}(\mathrm{X})$ in monosubstituted benzene derivatives. 
Table 3. $\operatorname{cSAR}(\mathrm{X})$ for $\mathrm{X}-\mathrm{Ph}-\mathrm{OH}$ and $\mathrm{X}-\mathrm{Ph}-\mathrm{O}^{-}$(Hirshfeld charges).

\begin{tabular}{|c|c|c|c|c|c|c|c|}
\hline \multirow[t]{2}{*}{$X$} & \multicolumn{3}{|c|}{$\mathrm{X}-\mathrm{Ph}-\mathrm{OH}$} & \multicolumn{3}{|c|}{$\mathrm{X}-\mathrm{Ph}-\mathrm{O}^{-}$} & \multirow[t]{2}{*}{$\Delta$} \\
\hline & para & meta & $\Delta 1$ & para & meta & $\Delta 2$ & \\
\hline $\mathrm{O}$ & -0.162 & -0.122 & 0.040 & -0.439 & -0.270 & 0.169 & 0.317 \\
\hline $\mathrm{NO}_{2}$ & -0.163 & -0.129 & 0.035 & -0.441 & -0.276 & 0.165 & 0.312 \\
\hline $\mathrm{CN}$ & -0.167 & -0.138 & 0.029 & -0.373 & -0.272 & 0.101 & 0.235 \\
\hline $\mathrm{COCl}$ & -0.162 & -0.123 & 0.039 & -0.463 & -0.308 & 0.155 & 0.340 \\
\hline $\mathrm{CF}_{3}$ & -0.113 & -0.087 & 0.026 & -0.314 & -0.219 & 0.095 & 0.227 \\
\hline $\mathrm{COMe}$ & -0.097 & -0.063 & 0.034 & -0.362 & -0.222 & 0.139 & 0.299 \\
\hline $\mathrm{COOH}$ & -0.115 & -0.082 & 0.033 & -0.368 & -0.232 & 0.136 & 0.286 \\
\hline $\mathrm{CHO}$ & -0.130 & -0.096 & 0.034 & -0.382 & -0.244 & 0.138 & 0.286 \\
\hline $\mathrm{CONH}_{2}$ & -0.079 & -0.048 & 0.031 & -0.333 & -0.201 & 0.132 & 0.285 \\
\hline $\mathrm{Cl}$ & -0.064 & -0.037 & 0.027 & -0.228 & -0.180 & 0.048 & 0.191 \\
\hline$\Gamma$ & -0.044 & -0.019 & 0.024 & -0.176 & -0.128 & 0.049 & 0.157 \\
\hline $\mathrm{H}$ & -0.017 & 0.007 & 0.024 & -0.146 & -0.087 & 0.059 & 0.15 \\
\hline $\mathrm{Me}$ & 0.013 & 0.039 & 0.026 & -0.147 & -0.088 & 0.059 & 0.18 \\
\hline $\mathrm{OMe}$ & 0.042 & 0.073 & 0.031 & -0.133 & -0.074 & 0.059 & 0.20 \\
\hline $\mathrm{OH}$ & 0.030 & 0.058 & 0.028 & -0.126 & -0.067 & 0.058 & 0.18 \\
\hline $\mathrm{NH}_{2}$ & 0.072 & 0.108 & 0.035 & -0.130 & -0.044 & 0.087 & 0.23 \\
\hline $\mathrm{NMe}_{2}$ & 0.095 & 0.137 & 0.042 & -0.169 & -0.086 & 0.083 & 0.30 \\
\hline range & 0.262 & 0.275 & 0.018 & 0.337 & 0.265 & 0.121 & \\
\hline
\end{tabular}

$\Delta 1, \Delta 2$, and $\Delta$ denote range of cSAR variability for particular $\mathrm{X}$ in phenols, phenolates, and both series, respectively

interactions (effects) of substituents from para position are stronger than from meta ones as observed for phenolates ( 0.337 and 0.265 , respectively). This not the case for phenol derivatives. The impact of $\mathrm{OH}$ group on electron attracting/ donating properties of the substituents is greater in meta position (range 0.275 ) than in para one (0.262).

\section{Conclusions}

The quantum chemical-based modeling of substituent effects in meta-substituted and para-substituted phenol and phenolate derivatives (SESE and cSAR characteristics) as well as the comparison of the obtained results with $\sigma$ constants allow for the deeper recognition of the nature of mutual interactions between substituents.

Firstly, it should be stated that the application of various atomic charge assessments (Hirshfeld, NBO, and AIM) for calculation of cSAR characteristics leads to a qualitatively equivalent picture of the studied problem.

The results of the analysis of interdependences of the substituent effect descriptors have demonstrated their usefulness for characterization of the substituent. For para-substituted systems, $\sigma_{\mathrm{p}}{ }^{-}$constants have been found to be better substituent effect parameters than $\sigma_{\mathrm{p}}$ ones, particularly in the case of phenolate derivatives. The relations of $\operatorname{cSAR}(\mathrm{X})$ vs. $\sigma$ have shown almost identical sensitivity of the substituent effect in meta-substituted phenol and phenolate derivatives, whereas they have indicated different kinds of intramolecular interactions in para-substituted phenols and phenolates.

The electron-attractive property of $\mathrm{OH}$ group in metasubstituted phenol derivatives causes the dramatically different picture of dependences of $\operatorname{cSAR}(\mathrm{X})$ on SESE as compared to that observed for all others (meta phenolate systems and para derivatives of phenols and phenolates). Moreover, it has been documented that $\mathrm{OH}$ group affects the electron-attracting and electron-donating substituents in meta positions in a different way.

The obtained Hammett-type dependences of $\operatorname{cSAR}(\mathrm{Y})$ on $\operatorname{cSAR}(\mathrm{X})$, where $\mathrm{Y}=\mathrm{OH}$ or $\mathrm{O}^{-}$, have revealed a stronger intramolecular interactions in para-substituted phenolates than phenol derivatives, whereas the opposite situation has been encountered for meta derivatives.

A clear substituent effect on $\pi$-electron delocalization of the benzene ring (the transmitting moiety of the studied systems) has been observed only in para-substituted phenolate derivatives - aromaticity of the ring increases in line with increasing $\operatorname{cSAR}(\mathrm{X})$ of the substituent. Additionally, it has been shown that the $p$ EDA parameter is useful to indicate changes in the $\pi$-electron structure of the ring due to the substituent effect.

An application of $\operatorname{cSAR}(\mathrm{X})$ for phenol derivatives has allowed to estimate that difference between $\operatorname{cSAR}(\mathrm{X})$ for meta and para derivatives may be as large as $\sim 15 \%$ of the range of the $\operatorname{cSAR}(\mathrm{X})$ variability, $\Delta$. In the case of phenolates, this difference may be even greater and amounts up to $\sim 53 \%$. The value of $\boldsymbol{\Delta}$ for a particular substituent represents its potential variability of its electron attracting/donating properties dependent on the moiety to which it is attached. This may have some general significance and should be taken into account when new systems are subject of studies.

Acknowledgements H.S. gratefully acknowledges the Interdisciplinary Center for Mathematical and Computational Modeling (Warsaw, Poland) for providing computer time and facilities. H.S. and T.M.K. thank the National Science Center and Ministry of Science and Higher Education of Poland for supporting this work under the grant no. UMO-2013/11/B/ ST4/00531.

\section{Compliance with ethical standards}

Conflict of interest The Authors declare that they have no conflict of interest.

Open Access This article is distributed under the terms of the Creative Commons Attribution 4.0 International License (http:// creativecommons.org/licenses/by/4.0/), which permits unrestricted use, distribution, and reproduction in any medium, provided you give appropriate credit to the original author(s) and the source, provide a link to the Creative Commons license, and indicate if changes were made. 


\section{References}

1. Szatylowicz H (2008) J Phys Org Chem 21:897-914

2. Gilli G, Gilli P (2009) The Nature of the Hydrogen Bond. Oxford Science Publications, Oxford

3. Hansch C, Leo A, Taft RW (1991) Chem Rev 91:165-195

4. Brown HC, Okamoto Y (1958) J Am Chem Soc 80:4979-4987

5. Clementi S, Linda P (1970) Tetrahedron 26:2869-2873

6. Pross A, Radom L, Taft RW (1980) J Org Chem 45:818-826

7. Sadlej-Sosnowska N (2007) Chem Phys Lett 447:192-196

8. Krygowski TM, Sadlej-Sosnowska N (2011) Struct Chem 22:17-22

9. Siodla T, Oziminski WP, Hoffmann M, Koroniak H, Krygowski TM (2014) J Org Chem 79:7321-7331

10. Szatylowicz H, Siodla T, Stasyuk OA, Krygowski TM (2016) Phys Chem Chem Phys 18:11711-11721

11. Stasyuk OA, Szatylowicz H, Fonseca Guerra C, Krygowski TM (2015) Struct Chem 26:905-913

12. Sadlej-Sosnowska N, Krygowski TM (2009) Chem Phys Lett 476: 191-195

13. Szatylowicz H, Jezuita A, Ejsmont K, Krygowski TM (2017) Struct Chem. doi:10.1007/s11224-017-0922-2

14. Varaksin KS, Szatylowicz H, Krygowski TM (2017) J Mol Struct 1137:581-588

15. Hehre WJ, Radom L, Schleyer PR, Pople JA (1986) Ab Initio Molecular Orbital Theory. John Wiley \& Sons, New York, p. 363

16. Rappaport Z (ed) (2003) The Chemistry of Phenols. Wiley, New York

17. Zabicky J, Rappoport Z, Liebman JF, Marek I (2014) The Chemistry of metal phenolates. Wiley, New York

18. Treutter D (2010) Int J Mol Sci 11:807-857

19. Burton SG (2003) Curr Org Chem 7:1317-1331

20. Zanotti I, Dall'Asta M, Mena P, Mele L, Bruni R, Ray S, Del Rio D (2015) Food Funct 6:13-31

21. Raczyńska ED, Kosińska W, Ośmiałowski B, Gawinecki R (2005) Chem Rev 105:3561-3612

22. Brovarets OO, Hovorun DM (2013) J Biomol Struct Dyn 31:913-936

23. Jaffe HH (1953) Chem Rev 53:191-261

24. Becke AD (1993) J Chem Phys 98:5648-5652

25. Lee C, Yang W, Parr RG (1988) Phys Rev B 37:785-789

26. Ditchfield R, Hehre WJ, Pople JA (1971) J Chem Phys 54:724-728

27. Frisch MJ, Trucks GW, Schlegel HB, Scuseria GE, Robb MA, Cheeseman JR, Scalmani G, Barone V, Mennucci B, Petersson GA, Nakatsuji H, Caricato M, Li X, Hratchian HP, Izmaylov AF, Bloino J, Zheng G, Sonnenberg JL, Hada M, Ehara M, Toyota K, Fukuda R, Hasegawa J, Ishida M, Nakajima T, Honda Y, Kitao O, Nakai H, Vreven T, Montgomery Jr JA, Peralta JE, Ogliaro F,
Bearpark M, Heyd JJ, Brothers E, Kudin KN, Staroverov VN, Kobayashi R, Normand J, Raghavachari K, Rendell A, Burant JC, Iyengar SS, Tomasi J, Cossi M, Rega N, Millam MJ, Klene M, Knox JE, Cross JB, Bakken V, Adamo C, Jaramillo J, Gomperts R, Stratmann RE, Yazyev O, Austin AJ, Cammi R, Pomelli C, Ochterski JW, Martin RL, Morokuma K, Zakrzewski VG, Voth GA, Salvador P, Dannenberg JJ, Dapprich S, Daniels AD, Farkas Ö, Foresman JB, Ortiz JV, Cioslowski J, Fox DJ (2009) GAUSSIAN 09 (Revision B.01) Gaussian Inc, Wallingford CT

28. Hehre WJ, McIver Jr RT, Pople JA, Schleyer PR (1974) J Am Chem Soc 96:7162-7173

29. Radom L (1974) J Chem Soc, Chem Commun 403-404. doi:10. 1039/C39740000403

30. Cyranski MK (2005) Chem Rev 105:3773-3811

31. Sadlej-Sosnowska N (2007) Polish J Chem 81:1123-1134

32. Hirshfeld FL (1977) Theor Chim Acta 44:129-138

33. Bader RWF (1990) Atoms in molecules: a quantum theory. Clarendon Press, Oxford

34. Weinhold F, Landis CR (2005) Valency and bonding. Cambridge University Press, Cambridge, A natural bond orbital donor-acceptor perspective

35. Bader RWF (2002) AIM 2000, Version 2.0, Ontario, Canada, McMaster University

36. Glendening ED, Badenhoop JK, Reed AE, Carpenter JE, Bohmann JA, Morales CM, Landis CR, Weinhold F (2013) NBO 6.0, Theoretical Chemistry Institute, University of Wisconsin, Madison

37. Ozimiński WP, Dobrowolski JC (2009) J Phys Org Chem 22:769-778

38. Kruszewski J, Krygowski TM (1972) Tetrahedron Lett 13: 3839-3842

39. Krygowski TM (1993) J Chem Inf Comput Sci 33:70-78

40. Cheeseman JR, Trucks GW, Keith TA, Frisch MJ (1996) J Chem Phys 104:5497-5509

41. Schleyer PR, Maerker C, Dransfeld A, Jiao H, Hommes NJRE (1996) J Am Chem Soc 118:6317-6318

42. Schleyer PR, Manoharan M, Wang ZX, Kiran B, Jiao H, Puchta R, Hommes NJRE (2001) Org Lett 3:2465-2468

43. Chen Z, Wannere CS, Corminboeuf C, Puchta R, Schleyer PR (2005) Chem Rev 105:3842-3888

44. Taft RW, Ehrenson S, Lewis IC, Glick RE (1959) J Am Chem Soc 81:5352-5361

45. Exner O (1972) In: Chapman NB, Shorter J (eds) Advances in Linear Free Energy Relationships. Plenum Press, London, p. 1 Chpt. 1

46. Krygowski TM, Ejsmont K, Stepien MK, Poater J, Sola M (2004) J Org Chem 69:6634-6640

47. Krygowski TM, Oziminski WP, Cyranski MK (2012) J Mol Model 18:2453-2460 